\title{
Overcoming the Improvement Paradox
}

\author{
Elizabeth K. Keating ${ }^{1}$ \\ Rogelio Oliva ${ }^{2}$ \\ Nelson P. Repenning ${ }^{1}$ \\ Scott Rockart ${ }^{1}$ \\ John D. Sterman ${ }^{1}$
}

European Management Journal , Vol. 17, No. 2, pp. 120-134, 1999

This work has been supported by the National Science Foundation (Grant SBR-9422228), Analog Devices, AT\&T, Ford Motor Company, Harley-Davidson, Lucent Technologies Inc., and National Semiconductor Corporation. We are grateful to the people of these firms for their outstanding help in this research. They generously provided financial support, their data and considerable amounts of their most precious resource - their time.

Please direct correspondence to John Sterman, MIT Sloan School of Management, Cambridge MA 02142 or jsterman@ mit.edu. Further information is available through http://web.mit.edu/jsterman/www.

\footnotetext{
${ }_{2}^{1}$ MIT Sloan School of Management, Cambridge, MA

${ }^{2}$ Harvard Business School, Boston, MA
} 


\section{Abstract}

Despite the demonstrated benefits of improvement programs such as total quality management and reengineering, most improvement programs end in failure. Companies have found it extremely difficult to sustain even initially successful process improvement programs. Even more puzzling, successful improvement programs sometimes worsen business performance, triggering layoffs, low morale, and the collapse of commitment to continuous improvement. We term this phenomenon the "Improvement Paradox." For the last four years, we have worked with a variety of firms to understand the paradox and design policies to overcome it. Our findings suggest that the inability to manage an improvement program as a dynamic process is the main determinant of program failure. Improvement programs are tightly coupled to other functions and processes in the firm, and to the firm's customers, suppliers, competitors and capital markets. Failure to account for the feedbacks among these tightly coupled activities leads to unanticipated and often harmful side effects. We describe these dynamics and offer some guidance for managers seeking to design sustainable process improvement programs.

\section{Keywords:}

Improvement initiatives, Process Improvement, TQM, Quality, Reengineering, System Dynamics. 


\section{Introduction}

Process improvement has become an imperative for businesses seeking competitive advantage,

yet it is disturbing how few organizations make lasting and successful use of process

improvement tools such as total quality management and reengineering. These tools should help

to raise productivity, boost quality and enhance competitiveness. However, quality programs

often struggle to gain initial acceptance and to sustain continuous improvement (US General

Accounting Office, 1991; Young, 1991a; Young, 1991b). Despite the demonstrated benefits of many improvement techniques, most attempts by companies to use them have ended in failure

(Easton and Jarrell, 1998). In fact, companies have found it extremely difficult to sustain even initially successful process improvement programs. Even more puzzling, successful improvement programs have sometimes led to declining business performance, causing layoffs, low morale, and the collapse of commitment to continuous improvement. We term this phenomenon the "Improvement Paradox."

If improvement tools were ineffective it would be easy to explain their low use. The evidence, however, does not support that explanation. Firms that win quality awards have higher shareholder returns (Hendricks and Singhal, 1996). Easton and Jarrell (1998) found that among the top 1,000 publicly held companies in the United States, firms with well developed quality programs significantly outperform their counterparts in profitability, share price and return on assets.

These large sample results are consistent with our own findings. In hundreds of hours of interviews with our partner companies, discussing both successful and unsuccessful programs, we rarely heard "the program was just no good." Typical comments on stalled or abandoned programs were "I believe [a particular program] is a good process. Some day I'd really like to 
work on a project that actually follows it" and "We've left a lot on the table by letting this program go." Our findings suggest that the inability to manage an improvement program as a dynamic process - one tightly coupled to other processes in the firm and to the firm's customers, suppliers, competitors and capital markets-is the main determinant of program failure. Failure to account for feedback from these tightly coupled activities leads to unanticipated, and often harmful, side effects that can cause the premature collapse and abandonment of otherwise successful improvement programs. We describe these dynamics and offer some guidance for managers seeking to design sustainable process improvement programs.

For the last four years we have worked with managers at Ford Motor Company, HarleyDavidson, Lucent Technologies, and National Semiconductor Corporation to understand why improvement programs often fail, and how practitioners can design sustainable improvement programs (Jones et al., 1996; Sterman et al., 1996). This work extends earlier research on the paradoxically poor financial performance experienced by Analog Devices shortly after a highly successful manufacturing improvement program (Sterman, Repenning, and Kofman, 1997). Our research involved detailed field studies with our partner organizations. We stressed multiple data sources including extensive interviews and archival data on the various metrics of quality, product histories, internal company materials, and financial results. We used the system dynamics method (Forrester, 1961) to understand the multiple feedback mechanisms that affect the implementation of improvement programs, and to formulate integrative formal models to test our hypotheses. 
Our findings span both the internal dynamics of an improvement program and the interactions of a program with forces outside the intended area of improvement focus. We first describe the internal dynamics of an improvement program and the managerial challenges they create. We then examine how an improvement program interacts with other improvement initiatives, other organizational units, and with customers. Other improvement programs, organizational practices, and market response have a profound influence on whether programs can be sustained and contribute to the improved performance of the entire company.

\section{Internal Dynamics of Improvement Programs}

Well-functioning quality programs cannot be bought, like a machine tool. No one can go out and purchase a fully functioning 6-sigma quality program. A competence in improvement must be grown organically. To do so management must grapple with three central issues. First, managers need to address the fundamental trade-off between current and future performance levels. Second, managers need to make sure that the source of commitment to ongoing improvement effort shifts from managerial actions to employee initiative. Finally, as a program succeeds, and so-called low-hanging fruit is harvested, managers need to adapt their improvement tools and manage expectations for continued gains.

\section{Fundamental improvement trade-off}

Process improvement theorists assert that the employees doing a job are the best-informed experts and should be responsible for identifying improvement opportunities and implementing changes (Deming, 1986; Ishikawa, 1985; Juran, 1969). Accordingly, most improvement initiatives rely on the employees who perform the day-to-day work to both guide the improvement program and make the actual improvements. The rationale behind this strategy is 
two-fold. First, employees already understand their process, reducing data collection and diagnosis time. Second, employees have a strong interest in implementing changes when they develop the proposals themselves. Deming (1986) argued, in what he called the "productivity chain", that resources freed up by productivity gains should be reinvested into the search for still greater improvements, creating self-reinforcing feedback stimulating continuous improvement. Operationally, effort allocated to improvement raises productivity, boosting process throughput, thereby lowering production pressure and yielding still more time for improvement (loop R1 in Figure 1). An organization that reinvests early improvement gains in further improvement effort creates a powerful positive feedback that generates ever-greater gains in quality and productivity.

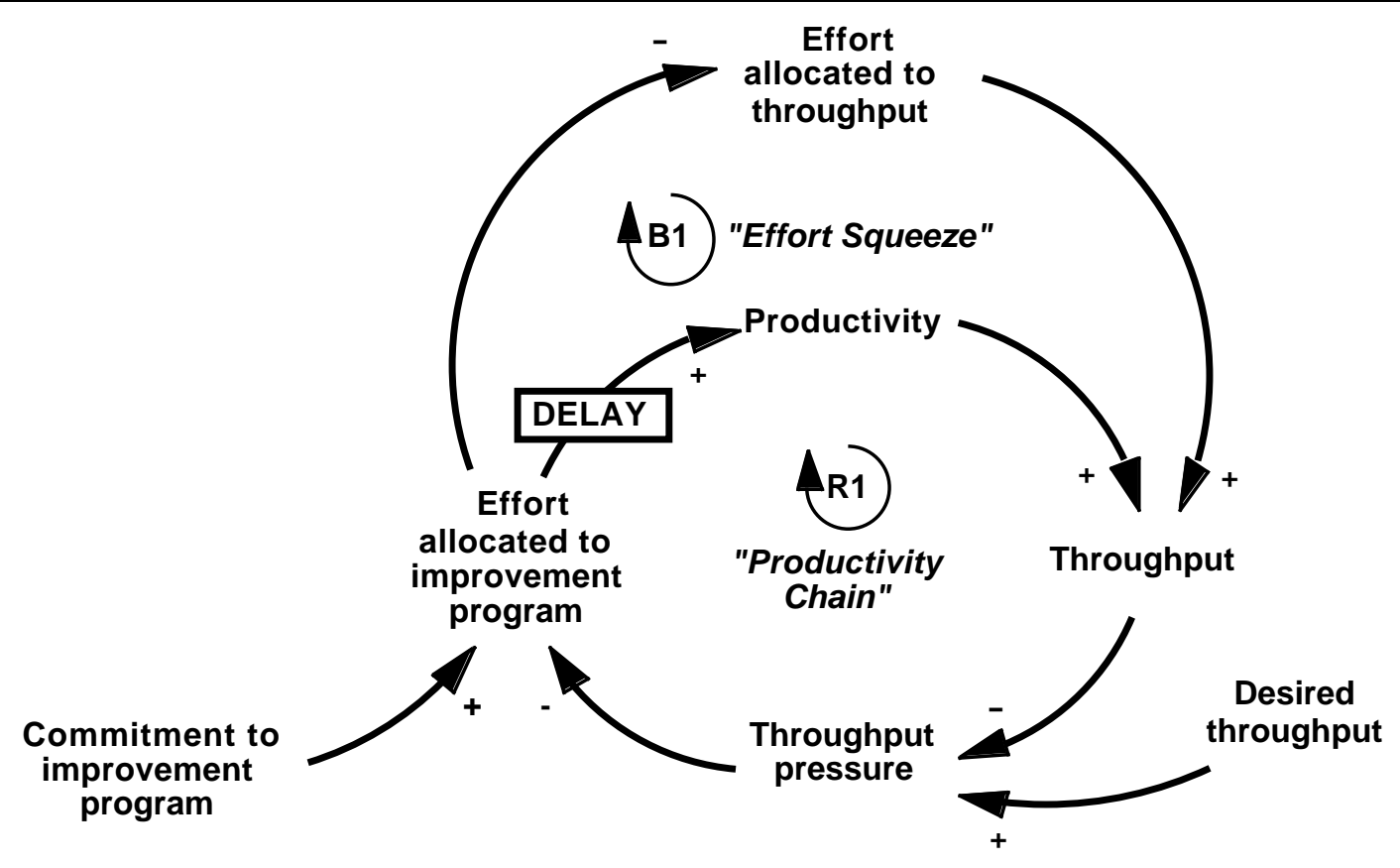

Figure 1: Improvement can be self-reinforcing

Arrows indicate the direction of causality: Signs ("+" and "-") at arrowheads indicate the polarity of relationships: a "+" denotes that an increase in the independent variable causes the dependent variable to increase, ceteris paribus (and a decrease causes a decrease). Similarly, a "-" indicates that an increase in the independent variable causes the dependent variable to decrease. Time delays are indicated in the diagram by a delay box. Reinforcing loop polarity (denoted by $\mathrm{R}$ in the loop identifier) indicates a self-reinforcing (positive) feedback process. Balancing (B) loop polarity indicates a regulating (negative) feedback process. 
However, reliance on operating employees to guide and implement improvement can limit the reinforcing process of the productivity chain. Imagine a quality program designed to reduce defects and boost usable output. It takes time for improvement effort to bear fruit. Therefore, the first effect of an increase in improvement effort is a reduction in the time employees can devote to throughput. The short run effect of improvement effort is a decline in output, exactly the opposite of the goal. As throughput falls, pressure to work harder builds. Employees faced with high pressure to meet throughput goals will be forced to cut back the time devoted to improvement, boosting output but stalling productivity and quality growth (the "effort squeeze" loop B1 in Figure 1). A manager in one plant we studied captured the dilemma clearly:

In the minds of the [operations team leaders] they had to hit their pack counts [daily quotas]. This meant if you were having a bad day and your yield had fallen... you had to run like crazy to hit your target. You could say "you are making 20\% garbage, stop the line and fix the problem", and they would say, "I can't hit my pack count without running like crazy." They could never get ahead of the game (Repenning and Sterman 1997).

To overcome the quandary, process improvement advocates discourage numerical throughput quotas and encourage employees to allocate a portion of their normal workday to improvement effort (Deming, 1986). Managers can also reduce throughput pressure by adding more resources, thereby allowing sufficient time for both throughput and improvement, or by lowering desired throughput (perhaps by increasing prices or reducing the number of new projects undertaken). Managers must, however, be prepared for a period when throughput will drop or costs rise. While throughput drops immediately at the start of an improvement effort, productivity only rises after the substantial delay in organizing and deploy improvement efforts. The delay 
between allocating time to improvement and obtaining results, combined with the immediate drop in throughput, implies that performance will follow a 'worse-before-better' pattern.

Du Pont's efforts to improve maintenance and equipment availability (Carroll, Sterman, and Marcus, 1998; Sterman, Banaghan, and Gorman, 1992) provide a clear example of this worsebefore-better pattern (Figure 2). After a worldwide benchmarking study, Du Pont managers found that their plants had maintenance expenditures considerably higher than best practices, while machine reliability and equipment availability were considerably lower. Further diagnosis showed that most maintenance effort was reactive, with insufficient effort devoted to preventive maintenance (PM), training, spare part quality, and design improvements. Over time, cost cutting had slashed training and PM. Less preventive maintenance increased the breakdown rate, pulling still more resources out of PM and causing a still greater increase in breakdowns: the productivity chain (loop R1) operated as a vicious cycle. The high breakdown rate meant the cost of maintenance was higher, and equipment availability lower, than before the cost cutting began.

Escaping from the reactive maintenance trap requires a large increase in PM. But the first impact of an increase in PM is a decline in equipment availability and an increase in maintenance costs. Only after some time will the benefits of PM start to show up in reduced breakdown rates. Many prior improvement programs had failed because management could not understand or tolerate the initial drop in availability and rise in costs.

Stimulated by a system dynamics model, Du Pont created a training program designed to break out of the reactive maintenance trap. A key part of the program was helping people understand 
the worse-before-better tradeoff. Figure 2 shows the cost savings for a typical plant following introduction of the improvement program. As expected, the initial impact of the intervention was a rise in costs. Once the mean time between failures (MTBF) of equipment began to rise, there were fewer breakdowns to repair, freeing up still more time for PM and boosting reliability. Equipment availability rose while maintenance costs fell: the productivity chain now operated as a virtuous cycle. Plants adopting the program experienced sharp increases in the rate of improvement. Mean time between failure for pumps rose about $15 \%$ with each doubling of cumulative experience, and costs ultimately fell by an average of about $20 \%$. Comparable plants pursuing traditional approaches saw learning rates of only about $5 \%$ and a $7 \%$ rise in maintenance costs (Carroll et al., 1998).

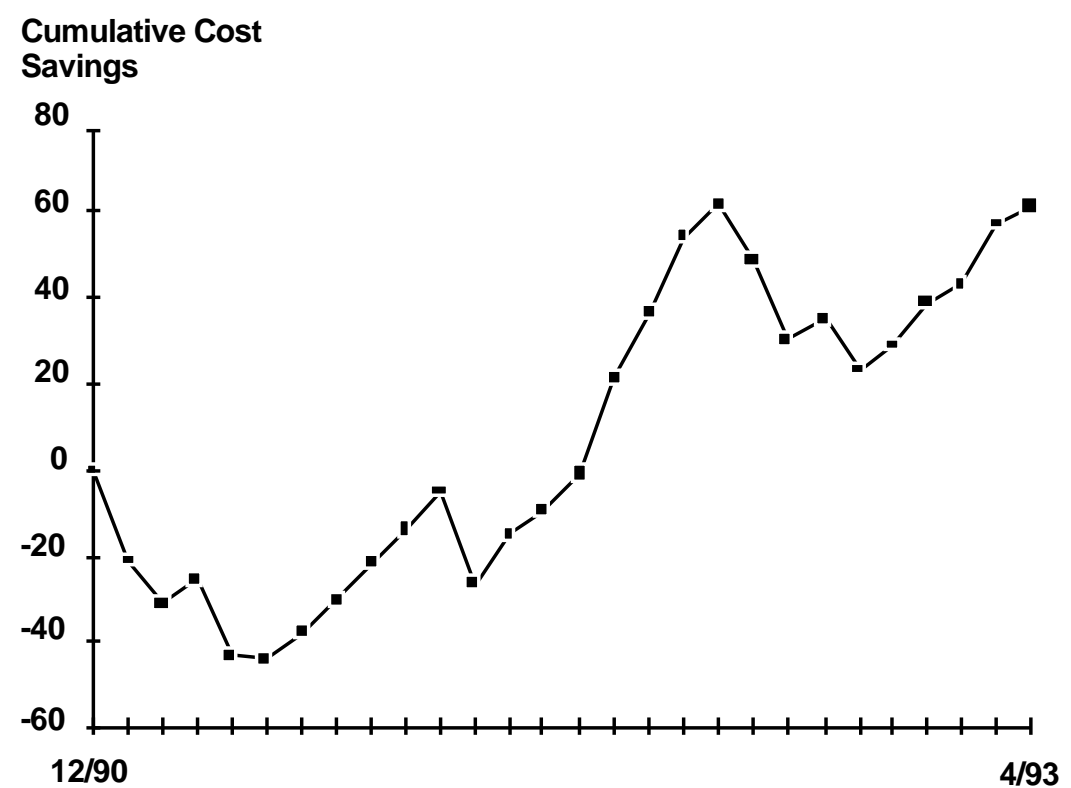

Figure 2: Cost savings at a typical Du Pont plant after implementing a preventive maintenance program. Vertical Scale disguised.

While some Du Pont facilities overcame the short-run deterioration in performance caused by improvement programs, many firms do not. Short-term performance goals tempt managers to 
harvest productivity gains by cutting costly resources or raising throughput targets. These actions intensify throughput pressure and shift effort away from improvement. Managers who fail to allocate enough resources find improvement efforts stall as workers devote their time to short-term throughput goals.

The tendency to harvest initial productivity gains by downsizing or increasing throughput objectives is strong. Anticipated productivity gains are often factored into equipment and labor planning. In several of the firms we studied, expected productivity gains from improvement efforts were assumed in projecting future labor and capital requirements. But goals based on unrealized productivity gains will be a source of throughput pressure and "effort squeeze" (loop B1 in Figure 1). In one case, the staff allocated to a critical activity was cut based on projected productivity gains from the improvement program. But the reduction in resources ensured that throughput pressure remained high, preventing the workforce from devoting sufficient time to improvement. The anticipated gains were never realized. Long lead times for new capacity and training delays for new employees meant that even after management realized their error it was too late to compensate. The improvement program failed.

To sustain a program, managers must support the reinforcing nature of improvement by limiting the effect of throughput pressure on effort allocation. An improvement program is more likely to succeed if managers facilitate a shift of employee time from throughput to improvement and limit opportunities for employees to shift effort back toward throughput. For example, in Ford's electronics division, managers prevented assembly workers from stealing time from improvement to boost short-run output by limiting the release of materials to the production floor. Once the 
materials allocated for the shift were used, operators could not run their machines and turned their attention to improvement opportunities.

\section{Initiating and sustaining employee commitment to improvement}

Freeing employees to improve processes is essential but insufficient. Successful improvement requires the enthusiastic commitment of employees since improvement activity is less structured and less easily monitored than throughput. Shiba et al. (1993) distinguish between two sources of commitment for improvement programs: managerial push and employee pull. Managerial push refers to efforts to promote improvement effort or mandate participation. These actions range from inspirational speeches about the importance of improvement to mandatory participation in training and improvement teams to financial incentives and performance review criteria based on improvement. Employee pull arises when workers come to understand the benefits of improvement for themselves and commit themselves to improvement effort independent of (and sometimes despite) management attitudes and support (Schaffer and Thomson, 1992). Our fieldwork suggests that developing employee pull is essential to sustaining improvement efforts.

Programs brought in by a high-level champion require a certain amount of management push to begin building commitment. Push techniques include providing training, demonstrating support, championing the value of the program, providing incentives, and clarifying the need to improve. For example, when Lucent Technologies launched the "Achieving Process Excellence" (APEX) initiative to reduce product development time, the efforts and persistence of project leader $\mathrm{Al}$ Hofmann and others served as an initial push for participation. Lucent (while still part of AT\&T) had attempted several times to apply various quality management tools to its product 
development process. These initiatives had failed, and many engineers in the organization were highly skeptical of the quality movement. To overcome this initial resistance, Hofmann lobbied his peers and his superiors to secure funding and release time from other responsibilities for the team members. He regularly sent notes of appreciation to participants and encouraged managers to recognize their staff members for APEX work. One team member recalled:

At first, people were 'volunteered' for teams by their managers, and people felt that APEX was a 'flavor of the month' project ... Hofmann put in a huge amount of personal time. He was committed to spend one-third of his time, but he often spent more. He worked hard to show that management cared. People then believed that management was serious (Keating and Oliva, forthcoming).

Managerial push often creates temporary excitement, but must be replaced by other sources of motivation when that excitement begins to fade. Even the most enthusiastic manager cannot personally contact everyone in a large organization, so as improvement activity spreads, the impact of individual leaders declines. Command-and-control structures are dependent on managerial supervision. They are unlikely to work in settings where employee participation and contributions are difficult to monitor and assess. Participants in failed efforts commonly report being unable or unwilling to continue after the program champion was promoted or reassigned. Employees accustomed to command-and-control management may never fully comprehend the program's underlying logic or embrace its goals. Participation becomes a matter of compliance to minimize conflict with superiors. When the push to participate is removed, compliance fades.

All successful initiatives we observed were driven by another self-reinforcing feedback. Initial commitment to a program, perhaps stimulated by management push, motivates improvement effort. With some delay, that effort leads to results. As employees see that the improvement process actually works, they start to believe it has some value, increasing commitment further in 
a self-reinforcing feedback (the "employee pull” loop R2 in Figure 3). At Lucent, this feedback

soon took off:

As a result of the growing success of APEX, people started to "self-identify" themselves for teams. These folks were really motivated; they generally came to the team with ideas that they were eager to implement. They were the ones who actively got things done.

No amount of management push can substitute for the self-reinforcing feedback created as results motivate more people to participate, thus generating more results. Management reshuffling regularly strips away program champions and replaces them with managers who may not share the interests or the skills of those who initiated existing programs. In these cases, it is the commitment of a stable set of employees that maintains the improvement efforts over time.

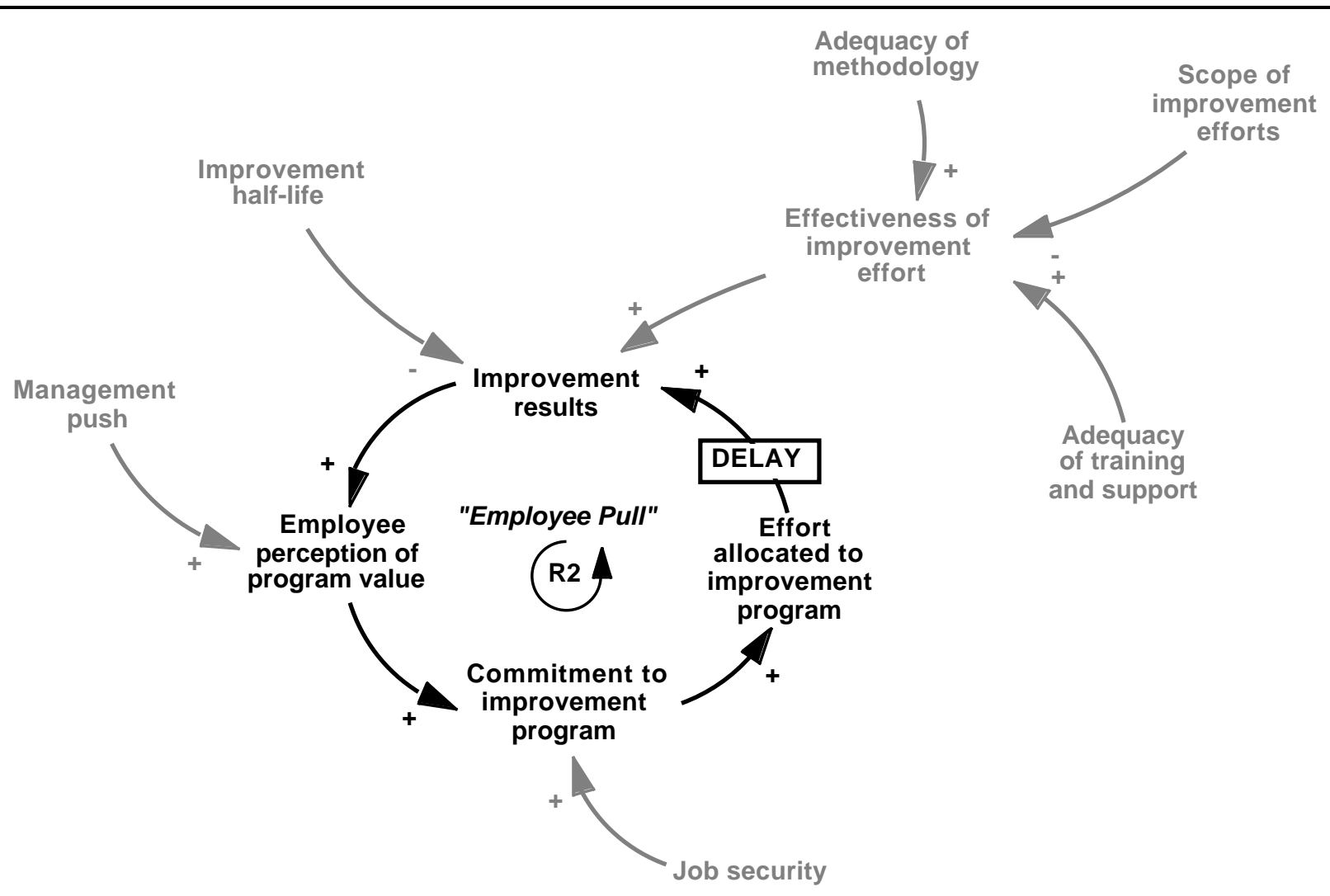

Figure 3: Self-reinforcing feedback drives employee commitment to improvement 
The employee pull feedback can function as a virtuous cycle (improvement boosts commitment, stimulating still more effort and improvement), or as a vicious cycle (poor results lead to less effort, ensuring still worse results).

As shown in figure 3, a variety of factors can interfere with the employee pull feedback raising the odds of a vicious cycle. First, complex processes are more difficult to improve (a complex process has a long "improvement half-life" - the time required to cut defects in half), intensifying the worse-before-better tradeoff and slowing the growth of commitment through employee pull. Second, the effectiveness of any improvement effort depends on the scope of the initiative and the adequacy of the chosen improvement methodology. Quality and reengineering tools are more highly developed for manufacturing and operations than for complex processes like product development, customer-vendor partnering, and senior management functions. Third, inadequate support infrastructure or training in improvement techniques limits the effectiveness of improvement effort. Finally, low job security can destroy commitment to improvement workers may shun improvement activity if they believe productivity gains will lead to layoffs. Each of these factors must be managed appropriately to generate the self-reinforcing commitment required for continuous improvement. We consider each constraint in turn.

\section{Employee Perception of Benefits}

Employee commitment to improvement increases when workers and line managers perceive that improvement effort works. In making the judgment that a program works, people compare the rate of progress they observe to their expectations. Commitment rises if progress is high relative to aspirations and falls when progress is disappointing. The dependence of commitment on observed progress means aggressive managerial push can adversely affects program success. For 
example, managers often set aggressive "stretch objectives", or so-called "BHAG's" (Big Hairy Aggressive Goals) to encourage participation in improvement programs (Hamel and Prahalad, 1989; Collins and Porras, 1994). For example, a senior manager in a large manufacturing firm set an aggressive goal to reduce manufacturing cycle time for the firm's plants from 18 days to 1 day in five years. He explained his rationale:

I didn't know if we could get to one day, and, to be honest, I really didn't care. If a facility was at 18 days and I set an objective of 16.5 days, everybody would have just squeezed a little bit. This way everybody knew they had to make big improvements. If they only made it to two days or three day that still would have been a lot better than 16.5 (Repenning and Sterman 1997).

While aggressive objectives may be helpful in creating initial push, they can undermine the development of long-term employee-pull effects. When objectives are set too high, expectations outstrip observed benefits and commitment falls, weakening the employee pull feedback. As shown in figure 4, stretch objectives can motivate greater effort by increasing people's aspirations as people "Rise to the Challenge" (loop B2 in Figure 4), but create a "Credibility Gap" that undermines effort when set too high (loop R3). As effort falls, performance suffers, confirming people's belief that the goal was infeasible. A vicious cycle of goal erosion and cynicism can set in. Few organizations undertaking ambitious change programs know what feasible rates of improvement in key metrics might be. It is all too easy for managers, themselves under pressure to meet the expectations of Wall Street or catch up to competitors, to set objectives far beyond the feasible range, leading to frustration and eroding their credibility. 


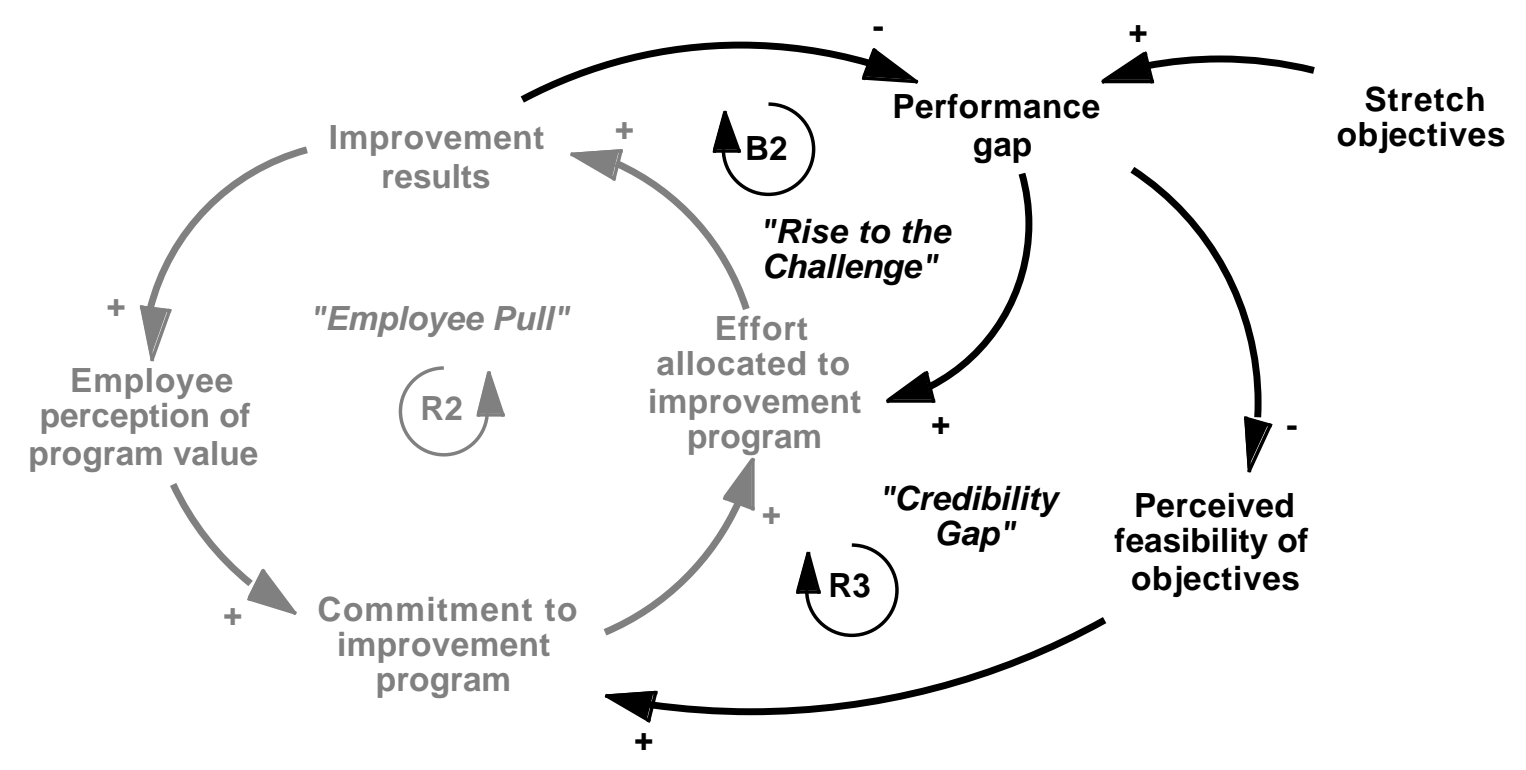

Figure 4: Stretch objectives and commitment

In the case above, the 1-day cycle time stretch objective was not well received, as the program leader recalled: "When I first announced [the one day objective], a lot of people just doubled over in pain. They really thought I was crazy." One member of the affected staff commented "At the time I thought to myself, 'I really hope I get transferred within the next five years because this is never going to happen. This guy just does not understand [our business].'”

To avoid frustration and abandonment of the improvement program, the senior manager allowed the improvement teams to define cycle time metrics and set their own goals at the operational level. Employees and lower level managers worked together to measure the "touch time" for each product (the time actually spent working on a product) as a fraction of overall cycle time. They were shocked to find that touch time was less than one percent of total cycle time. Reducing cycle time from eighteen days to one would still leave touch time less than twenty percent. Involving workers in the definition and measurement of cycle time and touch time helped everyone realize the goal was feasible, weakening the credibility gap loop. The program was a 
major success as initial results led to greater commitment and still lower cycle time throughout the division (Repenning and Sterman 1997).

\section{Complexity and the Improvement Half-Life}

Objective setting requires an answer to the question of "when" the goal will be achieved as well as to the question of "what" the goal is in absolute terms. Careful analysis of a firm's processes and benchmarking of other firm's processes can help to set aggressive yet realistic "what" goals for performance. These techniques do not, however, provide a sense of how long it will take to move from current to desired performance. People commonly underestimate the scope and difficulty of tasks (Kahneman and Lovallo, 1993) and expect benefits sooner than is reasonable. Thus even when the absolute goal (e.g. a one day cycle time) is set appropriately, the time provided to reach the goal is often far too short.

Reasonable estimates of the time required to improve are needed to allocate sufficient resources to improvement. An organization that continually underestimates the time required to realize results develops a demoralized and skeptical workforce that discounts managerial promises and will rely more heavily on tangible benefits. In one firm we studied, the workers had been through so many quality programs that they described each new one by the acronym "AFP" - Another 'Fine' Program.

One helpful concept in developing program objectives is the improvement half-life. Schneiderman (1988) found that in a wide variety of firms, "any defect level, subjected to legitimate QIP [quality improvement processes], decreases at a constant [fractional] rate.” The 
result is an exponential decline in defects characterized by the 'improvement half-life' - the time required for defects to fall by 50 percent (Figure 5).

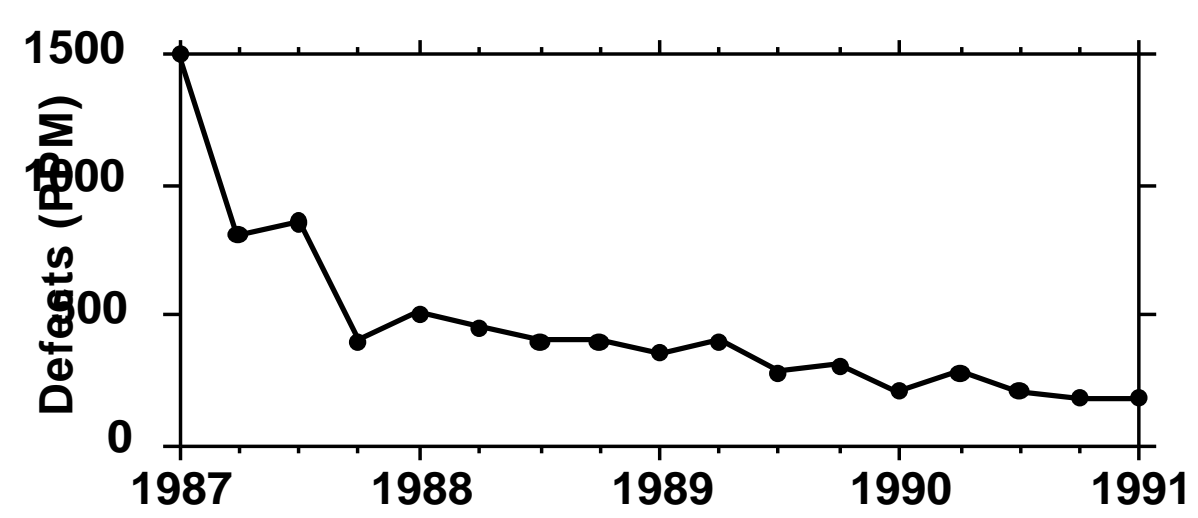

Figure 5: Semiconductor fabrication defects after the start of a TQM program. The improvement half-life is about 9 months.

The basis for the half-life dynamic is the Plan-Do-Check-Act learning loop or 'PDCA cycle' at the heart of TQM and other improvement techniques (Analog Devices, 1991; Shewhart, 1939). Improvement teams cycle around the PDCA learning loop. With each cycle a team identifies and eliminates the largest remaining root cause of defects, then moves on to the remaining sources of defects. The fractional rate of defect reduction each month $(\mathrm{R})$ is the product of the fractional improvement per cycle (I) and the number of cycles per month (L).

$$
\mathrm{R}=\mathrm{I} \cdot \mathrm{L}
$$

Consequently, the rate at which defects are generated (D) falls exponentially towards the theoretical minimum level $\mathrm{D}_{\min }$ at the fractional rate $\mathrm{R}$ (Schneiderman, 1988; Sterman et al., 1997, Zangwill and Kantor 1998):

$$
\mathrm{D}(\mathrm{t})=\mathrm{D}_{\min }+\left(\mathrm{D}_{0}-\mathrm{D}_{\min }\right) \exp (-\mathrm{Rt})
$$


The faster the rate of improvement $\mathrm{R}$, the shorter the improvement half-life will be (the half-life is given by $\ln (2) / \mathrm{R})$. Improvement half-lives vary across processes and functions. Simple processes like a single piece of equipment in a manufacturing cell were found to have half-lives on the order of a few months. Complex processes, like product development, have half lives on the order of several years. Schneiderman (1988) found that improvement half-lives grow with the technical and organizational complexity of a process (Figure 6). Greater technical complexity slows the improvement rate due to difficulties in designing, conducting, and interpreting experiments that might reveal approaches to defect reduction. Organizational complexity refers to the number and type of people, from different organizational functions, required to carry out an effective improvement effort for the process. Coordinating the marketers, product architects, designers, suppliers, finance people, and others involved in product development takes longer than getting the operators and mechanics responsible for a particular machine to meet. Greater complexity reduces both the learning per cycle and the number of improvement cycles the organization can carry out per month, slowing improvement.

Several characteristics can be used to determine the technical and organizational complexity of a process or function. Technical complexity is higher when (a) the process cycle time is long, (b) it is difficult to perform experiments, or (c) a high degree of technical know-how is required. Organizational complexity is higher when (a) many functions are involved, (b) separate organizations need to implement changes, (c) many people, from different backgrounds and with differing loyalties, are required to operate the process, or (d) scheduling meetings is difficult. 


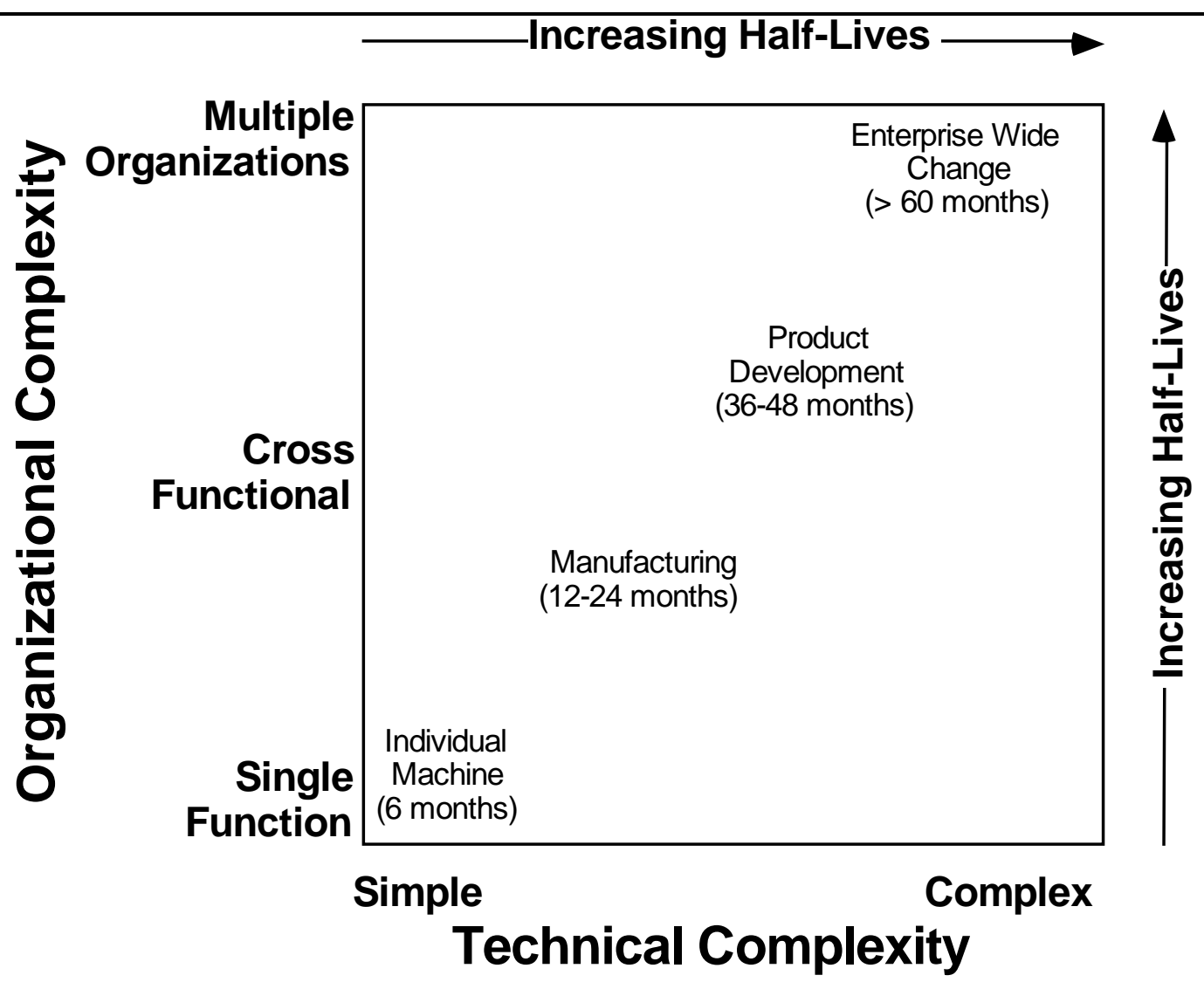

Figure 6: Improvement half-life

Source: Adapted from Schneiderman (1991)

The half-life concept provides a reality check on program goals. For example, a product engineering group in a research partner company was charged with cutting warranty costs in half by the year 2000. The group met in October 1997, and working backwards from the target date, realized that the needed changes would have to be completed by the summer of 1998, leaving less than one year to redesign a wide range of parts and associated tooling and develop new procedures and training materials. After locating their process in the upper right-hand corner of technical and organizational complexity, suggesting a half-life of several years, the group revised their goals. With less pressure, the engineers' morale and commitment to the effort improved, and their faith in their leadership rose. 


\section{Success and increasing complexity}

The half-life concept has also proven helpful in revising objectives over time. Early efforts tend to focus on relatively simple problems, low in technical and organizational complexity, for which known techniques can be easily applied - the famous "low hanging fruit" discussed in the quality literature. As the simpler problems are solved, the program must focus on problems with greater technical and organizational complexity, causing the improvement half-life to rise (the "tougher challenges" loop B3 in Figure 7). As the rate of improvement slows, the self-reinforcing employee pull process (loop R2) weakens, and programs can falter.

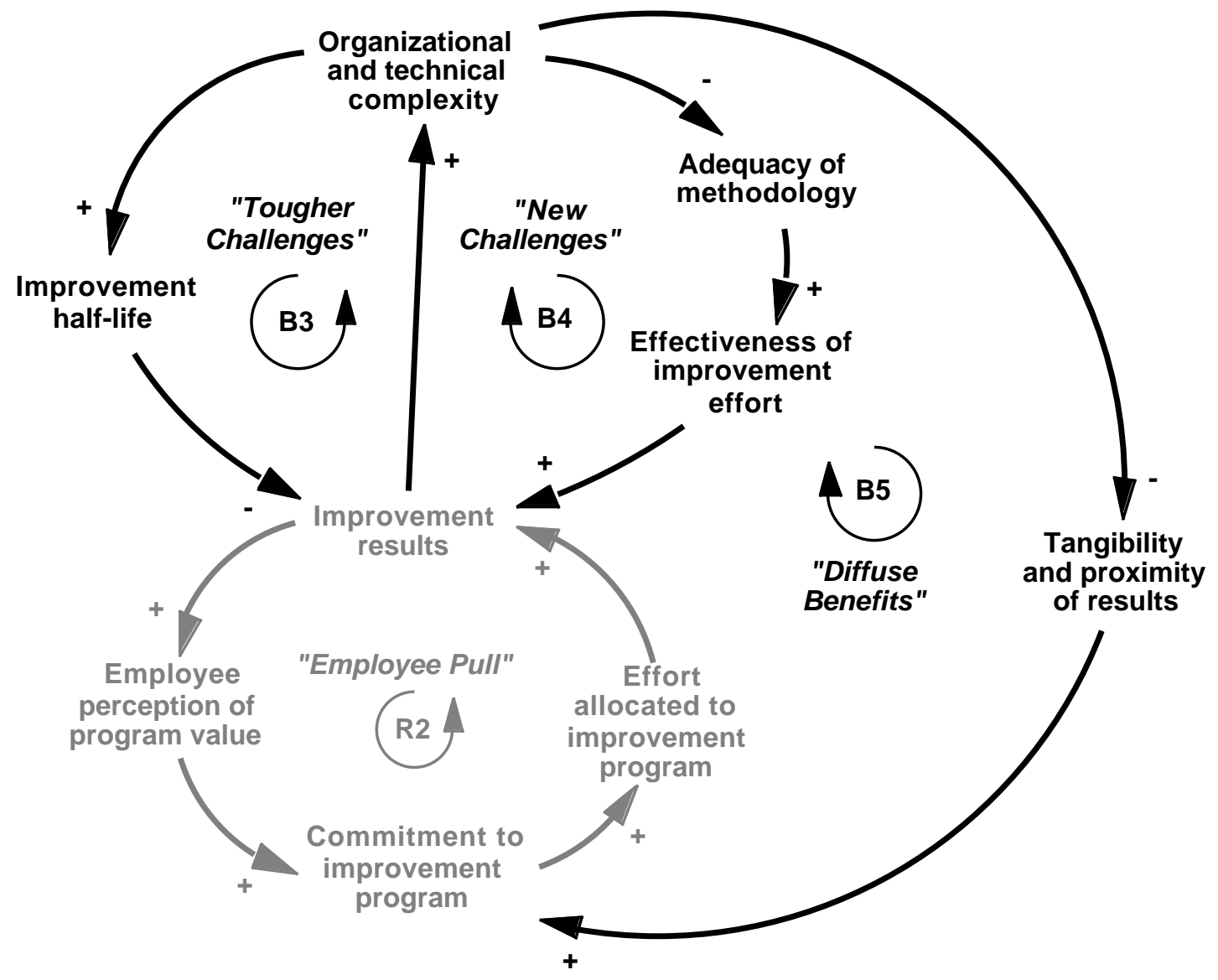

Figure 7: Increasing technical and organizational complexity 
The APEX initiative at Lucent Technologies faced this challenge (Keating and Oliva, forthcoming). Initially, Lucent decomposed the product development process into smaller subprocesses. Individual improvement teams tackled each activity in isolation. Focusing on the pieces of the process reduced organizational complexity and led to a short improvement half-life - at Lucent this process was described as "catching the fat rabbits." With a short half-life, product development time fell rapidly at first, demonstrating the value of the improvement program and boosting participation through the employee pull loop R2. Product development times fell from about 40 months to 20 in just two years.

However, the improvement teams soon exhausted opportunities within the sub-processes, threatening progress. The APEX leadership refocused their efforts on the interactions of the subprocesses. These issues - for example, the coupling between marketing, product definition, and engineering, or the linkages among different technology and product platforms - created tougher challenges involving greater technical complexity and much greater organizational complexity, slowing the rate of improvement (loop B3 in Figure 7). Improvement teams also found that the improvement methodologies that had worked so well at first became less and less adequate for the new challenges arising from the couplings among phases and activities (loop B4).

The APEX leadership responded to these challenges by investing in the development of new improvement tools more appropriate for the interactions across organizational units (requiring additional time be diverted from design work to training in improvement techniques). They revised their aspirations for future development time reduction to be more consistent with the 
growing complexity and difficulty of the task. Over the next two years, they cut product development times another $40 \%$.

Eventually, as the organizational scope and breadth of the improvement effort grew, it became harder to attribute results to particular individuals or teams. The rewards of participation fell, and people were less willing to tackle the problems (the "diffuse benefits" loop B5 in Figure 7). An APEX leader commented:

The integration effort was not an easy task to sell to management. The project was really tough to keep going since the benefits were for so many people. If you looked at it, the near term benefit to any one person was zero, so no one would work on it or pay for it. It is a common good, like clean water. It is too much to everyone's benefit.

Lucent's strategy in the successful APEX initiative highlights important lessons for the management of improvement programs. First, the rate of improvement of any process depends on its technical and organizational complexity. Objectives, and time frames for achieving them, need to be ambitious but consistent with the improvement half-lives of the process. However, the improvement half-life is not an immutable constant. Lucent's decision to focus initially on individual pieces of the product development process reduced organizational and technical complexity, lowering the half-life and speeding results. Given the history of failed improvement efforts, demonstrating that the new program worked was important to overcome initial resistance from the engineers. Lucent also recognized that initial improvement rates were high while the easy problems were solved, and adapted both their aspirations and their improvement methodology to keep pace with increasing technical and organizational complexity.

\section{Skill Dilution}

Generating enthusiasm among employees and reducing throughput pressure so they have time for 
improvement is far from sufficient. The employees involved require training and support.

Training, like improvement itself, cannot be bought and delivered instantly. It takes considerable time to develop training and support infrastructure (the "capacity building" loop R4). Training capacity includes qualified instructors, well versed in the specific set of techniques and the specifics of the organization, and customized materials. Active improvement teams also require support in the form of experienced people they can turn to for help, libraries of past projects and tools, and resources to implement their improvement ideas. Improvement programs can falter as aggressive push and pull effects that expand the demand for training and support far faster than capacity and support infrastructure (the "skill dilution" loop B6 in Figure 8). One organization we studied aggressively promoted a new improvement program, overwhelming the training organization. The initially enthusiastic participants then stumbled in applying the tools, causing them to question the methodology and, ultimately, abandon the program.

\section{Scope Creep}

A successful program can attract too much attention and lose focus. Initially successful programs attract the interest of more senior people in the organization and in other functions and departments. The program is then applied to problems far outside the scope of issues for which it was designed. Such "scope creep" (loop B7 in Figure 8) causes a successful program to be expanded to all sorts of problems for which it is ill suited, reducing the benefits obtained and further diluting worker skills and support infrastructure. In several organizations we studied, overzealous application of quality tools led to declining effectiveness and a backlash that damaged even the effective programs. 


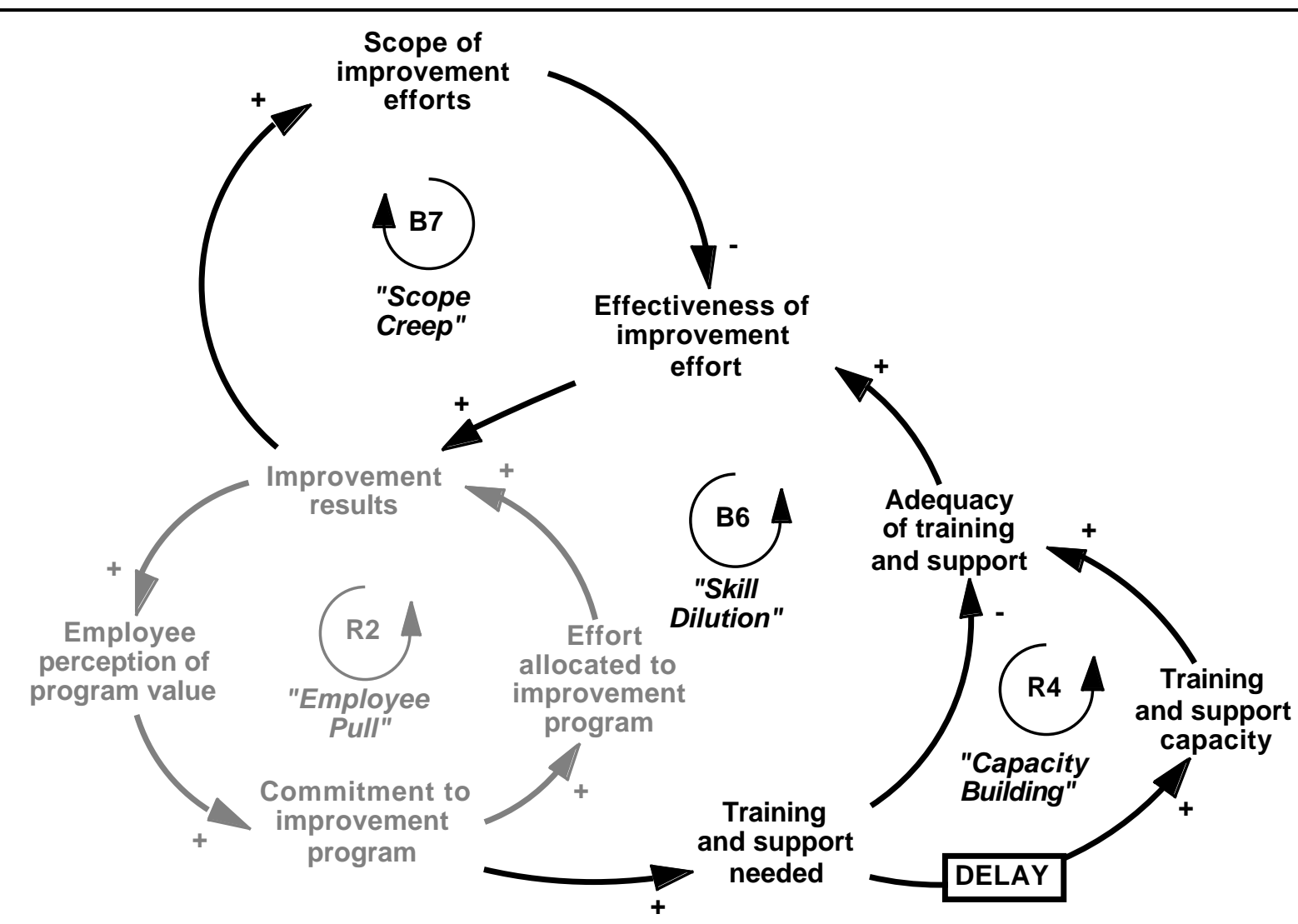

Figure 8: Scope creep and skill dilution

\section{External Interactions}

So far we have treated improvement programs in isolation. But improvement programs affect, and are affected by, other initiatives and other functions and organizations in the firm. One of our partner companies initiated an average of two new improvement program initiatives each year for the past fifteen years. Many programs were carried out simultaneously by overlapping groups in overlapping areas of focus (Oliva, Rockart, and Sterman, 1998). In other firms, improvement initiatives in manufacturing had profound effects on product development, pricing, human resources, inventory management, and even the financial markets. Many of these interactions were unexpected and harmful. 
Few organizations rely on only a single improvement effort. More often a stream of programs is implemented concurrently. Even when they address different issues, these programs are linked through shared resources including human effort, funding, information, and senior management attention. These interconnections can create substantial synergies across programs as well as damaging competition.

Multiple programs can lead to synergies. Successful programs help focus organizational awareness on the potential for improvement and the availability of improvement tools. Successful programs also generate commitment to improvement that can be transferred from one program to another. The techniques learned to support one program (e.g. process mapping) often carry over to other programs, shortening the time required to build competence and achieve results in subsequent initiatives. In many cases, the substantive knowledge built in one program helps to identify the specific organizational elements most in need of improvement and the skills needed for future improvement.

An example of these synergistic interactions is the use of Theory of Constraints (TOC) (Goldratt, 1990) and Total Productive Maintenance (TPM) (Nakajima, 1988) at one of the wafer fabrication plants of National Semiconductor Corporation. TOC is a method for improving throughput, lowering expenses, and managing material flow. The TOC program required managers to determine the capacity of each process step, then focus improvement on those processes that constrained throughput - the bottlenecks in the production flow. TPM focuses on increasing the capacity of individual process steps by encouraging machine operators to focus on preventive and predictive maintenance rather than reactive repairs. Armed with the results of 
the TOC analysis, TPM effort was focused on the bottleneck processes where increased capacity would boost factory throughput the most.

Interactions across programs can be detrimental. For example, a cycle time reduction effort in the electronics division of Ford led to dramatic improvements in manufacturing productivity. Initially, the improvement relieved throughput pressure and allowed line workers to dedicate even more time to improvement - the self-reinforcing productivity chain loop operated as a virtuous cycle. The program was so successful, however, that soon the plants developed excess capacity. The leader of the effort realized that if the excess capacity could not be used, a lay-off would be inevitable. "Empty plants," he said, "meant unaffordable plants."

To fill its underutilized manufacturing facilities the division launched a new initiative aimed at improving the throughput of the product development process. Getting new products into production faster would generate more demand and solve the excess capacity problem. The effort led to a new and superior product development process, involving better design and management tools (CAD/CAM, project management, a library of reusable, documented designs, and so on). While millions were spent, the program did not achieve its objectives. The initiative failed because product development engineers also face the fundamental trade-off - they can either spend their time on improvement or spend their time developing new products. Excess capacity in manufacturing led the organization to initiate the development of many new products. These new projects intensified the pressure on the development engineers at the same time they were being asked to implement the new process. A senior manager said, 
There was tremendous pressure to grow....We would get ourselves in situations where we would have a success... which translated into a resource problem for the engineers. We typically never said no (Repenning and Sterman 1997).

Under intense pressure to get new products into production, the engineers had no choice but to cut back the time they spent learning to use the tools and methods of the improved product development process. One engineer noted "the only thing they shoot you for is missing product launch. Everything else is negotiable." Many never learned to use the new multi-million dollar CAD/CAM system, and skimped on documentation, so the library of reusable designs never materialized. Because product development did not improve significantly, new products could not be launched fast enough to utilize the excess manufacturing capacity, and the division had to reduce headcount.

\section{Interactions with other organizational units}

Improvement programs interact with one another and with existing decision rules and organizational routines. Though subtle, these interactions can have dramatic effects, as the experience of Analog Devices shows. Over a period of three years, a spectacularly successful quality program at Analog Devices roughly doubled the manufacturing yield and slashed the defect rate of outgoing product. With lower production costs, higher yield, and better products, Analog should have realized dramatic improvement in financial results. Instead, the company's profits and stock price sank. The company's performance dropped not only in absolute terms, but relative to competitors who had not adopted TQM practices as quickly.

Dramatic improvements in yield, cycle time, and quality effectively doubled production capacity, outstripping improvement in other areas. Decision rules for production starts did not adjust as 
fast as yield improved, leading to excess inventory. Capacity grew much faster than demand, leading to fear of layoffs that undermined commitment to further improvement (the "fear of layoffs" loop B8 in figure 9). Excess capacity could be absorbed if higher quality and lower costs led to market share gains (the "better products" loop R5 in figure 9), or if new products could be brought to market faster (the "more products" loop R6). But Analog's market share did not rise appreciably because it was already the dominant firm in many markets and because competitors sought to preserve their market share by cutting prices. New product introduction could not rise fast enough due to its greater complexity and longer half-lives compared to manufacturing.

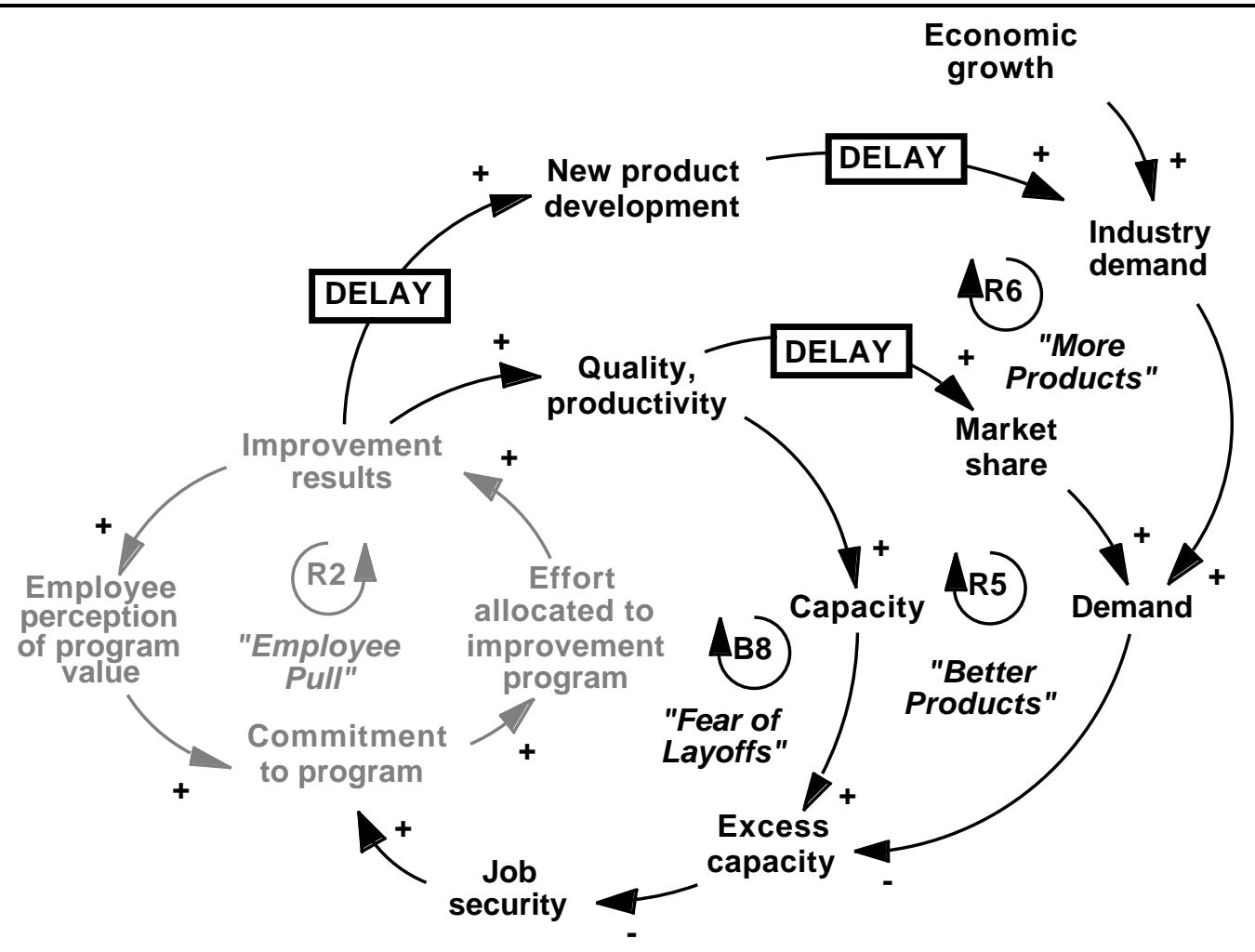

Figure 9: Interactions with the market and job security

Most important, rapid improvement in manufacturing caused a large decrease in unit direct costs.

However, indirect costs per unit, driven by R\&D and general, administrative, and selling expenses, did not improve as quickly due to their greater organizational and technical complexity. 
Thus while lowering costs overall, the TQM initiative also changed the traditional relationship between direct and indirect costs, a relationship embedded in organizational norms for pricing. Analog, like many firms with extensive product lines, used markup pricing. Unit direct costs were marked up by a standard ratio to yield a base price level, which was then adjusted on the margin to respond to market conditions. The traditional markup ratio, a little over $200 \%$, was initially sufficient to cover indirect costs and provide a reasonable return (Table 1). The traditional markup changed only slowly. Between 1985 and 1989, the success of the TQM program led to a drop of about $16 \%$ in unit direct costs, and average selling prices fell by about the same ratio. However, indirect costs per unit fell less than 9\%. Analog's traditional gross margins were no longer sufficient, and operating income fell by $45 \%$ (Table 1). The precipitous drop in profit lowered stock prices, and Analog responded by laying off $10 \%$ of the workforce, the first layoff in its history. Commitment to improvement plummeted as the "fear of layoffs" loop dominated the system (Sterman et al., 1997). Thus Analog's success in improving operations triggered unanticipated side effects that fed back to harm the firm and undercut continued improvement.

While Analog eventually rebounded, and a new crop of quality efforts eventually grew, the unanticipated side effects of rapid and unbalanced improvements damaged morale, disrupted continuous improvement, and threatened the survival of the firm. 


\begin{tabular}{|c|c|c|c|}
\hline \multicolumn{4}{|c|}{ Historical Data, Analog Devices } \\
\hline \$/unit & 1985 & 1989 & $\% \Delta$ \\
\hline Ave. Selling Price & 16.32 & 13.51 & -17.2 \\
\hline - Cost of Goods Sold & 7.61 & 6.41 & -15.8 \\
\hline$=\overline{\text { Gross Profit }}$ & 8.71 & 7.10 & -18.5 \\
\hline - Indirect Costs & 6.35 & 5.80 & -8.7 \\
\hline$=$ Operating Income & 2.36 & 1.30 & -44.7 \\
\hline $\begin{aligned} & \text { Markup Ratio (\%) } \\
= & 100^{*}(\mathrm{ASP} / \mathrm{COGS})\end{aligned}$ & 214 & 211 & -1.7 \\
\hline
\end{tabular}

Table 1. Changes in cost structure caused by TQM interacted with pricing policy to yield lower profit (all data expressed per unit sold).

Source: Sterman, Repenning and Kofman 1997.

\section{The Iron Law of Layoffs}

As the previous examples show, successful quality programs, by increasing yield and slashing scrap, defects, and cycle time, can lead to rapid growth in capacity. Unless demand grows

rapidly as well, the result is excess capacity and pressure for layoffs. Excess capacity is common since processes with low complexity and short improvement half-lives (e.g. scrap and cycle time reduction) tend to be capacity-augmenting, while demand-generating activities (e.g. new product development, customer needs assessment, and supply chain integration) have long improvement half-lives and involve long delays (figure 9).

A simple calculation reveals how fast productivity can grow before creating excess labor and pressure for layoffs. The labor requirements of any firm are given by sales divided by labor productivity. The fractional rate of change of labor requirements, $1^{*}$, is thus equal to the fractional growth in sales, $\mathrm{s}$, less the fractional rate of productivity growth, $\mathrm{p}$ :

$$
1^{*}=\mathrm{s}-\mathrm{p}
$$

Given the fractional attrition rate of the labor force (denoted ' $a$ '), the maximum rate of 
productivity growth consistent with a no-layoff policy is thus:

$$
\mathrm{p} \leq \mathrm{s}+\mathrm{a}
$$

This is the "Iron Law of Layoffs": Productivity improvement greater than the rate of sales growth plus the labor attrition rate necessarily creates excess capacity. The more successfully an organization improves its manufacturing operations, the more intense the pressure for layoffs. In Analog's case, sales growth averaged 27\% /year from its founding through 1985 and labor turnover was also high (10-20\%/year) as employees readily found new opportunities in the expanding electronics industry. Analog could have absorbed productivity growth of 40 to 50\%/year. However, as growth faltered and unemployment rose in the late 1980s and early ' 90 s, voluntary quits fell below 5\% per year. With negligible attrition and sales growth less than $10 \% / y e a r$, even small rates of improvement led to excess capacity.

The Iron Law of Layoffs provides several policy insights. Deming (1986) exhorts management to "drive out fear" by guaranteeing job security to workers who participate in improvement programs. But the Iron Law of Layoffs means that such commitments are often not credible. In mature, slow growth industries, or times of recession when voluntary attrition is low, it can be difficult to sustain commitment to improvement. Yet slow demand growth and weak economic conditions motivate firms to undertake ambitious improvement programs. Many firms launch improvement initiatives precisely when they are least able to absorb productivity gains without downsizing.

There are several policies a firm can use to resolve this dilemma. First, firms can sometimes convince workers that while improvement may cost some jobs, failure to improve will cost all 
jobs. This strategy, reversing Deming to "Drive in Fear", enables firms to credibly demonstrate that participation in improvement programs is in the employees' best interests despite the threat of job losses (Repenning, 1988). Second, improvement efforts can be directed at the slowimproving processes first, so that the rate of improvement in demand and capacity is more balanced.

\section{Interactions with the market}

Successful improvement can also create the opposite problem: too much demand. Improvement initiatives at one of our partner companies improved product quality dramatically. Prior to the quality program, the firm's products often had multiple defects requiring substantial maintenance and frequent repairs. Through an aggressive improvement program, quality rose dramatically, attracting large numbers of new customers.

The resulting market growth has been profound. Over a recent five-year period revenues grew at nearly $30 \% / y e a r$, much faster than production capacity. Huge backlogs meant many customers waited more than 18 months for delivery. The company struggled to meet the booming demand by reengineering manufacturing lines and aggressively hiring new workers. Production capacity doubled, but quality began to suffer:

In [one year], we moved four hundred machines [to double capacity in an existing plant] ...ripping [them] up, moving [them] to a new location, setting them up and going. Quality is at risk when you are doing all of that.

The effect of growth on quality is that you get your new bodies for making parts from the assembly line, [and] they are the less experienced workers.

The high workload threatened commitment to continued improvement. Workers throughout the organization, from the assembly line to product development, felt strong pressure to reduce the 
time devoted to improvement to boost near-term production (the "effort squeeze" loop in Figure 1). Interviews with line workers and engineers showed how the pressure to "get the iron out" deliver product to customers - eroded their commitment to quality:

Sometimes we use junk because management doesn't want us to shut the line down.

Sometimes you will take a part that is cosmetically defective - [with] a slight nick or scratch. They'll take that piece [and] say it is a reject [but when] the next day comes up and they are really short of those pieces, they'll take a few of those pieces back, and say, well it is not that bad.

Thus initial success in boosting quality fed back through the market to increase demand making it difficult to maintain the quality levels that led to their success.

\section{Conclusion}

The failure of promising programs is a symptom of the organizational and economic challenges involved in making them work. Managers are often unprepared for the interactions of improvement programs with processes outside the programs' apparent focus. The improvement paradox arises because it is difficult to anticipate the wide-ranging effects of improvement, especially when the intended changes are so clearly beneficial and the unintended adverse effects are delayed or occur in other functions or organizations.

Companies can strengthen the self-reinforcing processes that can lead to sustained improvement by actively managing the feedbacks that limit program success. Managers must carefully plan the roll-out of a new program to ensure demand for participation does not outstrip training and support infrastructure. Staffing, resources, and goals must be consistent with the improvement half-life of the process to prevent effort squeeze. If employees are free to allocate time to improvement, are adequately trained, and program scope remains focused, initial results will build 
commitment. By activating the virtuous cycle of employee pull early in the process, rapid productivity gains will follow, sustaining the program without command-and-control management.

However, managers should anticipate a slowdown in improvement results as the complexity of the problems addressed increases. Managers may need to adopt new process improvement techniques to reduce complexity. Management must also recognize the feedbacks arising from other improvement programs, organizational units and the market. Decision rules and procedures throughout the organization should be reviewed even if they do not appear to be affected by the improvement program. In short, managers must become adept in understanding their organization as a dynamic system.

At our partner companies this process is currently under way. We have developed a management flight simulator and learning environment addressing the issues discussed here. These tools allow managers to manage simulated improvement programs, experience the longterm and distant side effects of their actions, and design new strategies for the improvement programs they are leading. Our current research focuses on evaluating and improving the learning laboratory and assessing its impact as a catalyst for the change in organizations. 


\section{References}

Analog Devices (1991) TQM at ADI . Analog Devices, Norwood, MA.

Carroll, J., Sterman, J., and Marcus, A. (1998). Playing the maintenance game: How mental models drive organizational decisions. In Halpern, J. and Stern, R. (Eds.), Debating rationality: Nonrational elements of organizational decision making (pp. 99-121). Ithaca, NY: Cornell University Press.

Collins, J., and Porras, J. (1994) Build to last: Successful habits of visionary companies. Harper Business, New York.

Deming, W.E. (1986) Out of the crisis. MIT Press, Cambridge, MA.

Easton, G., and Jarrell, S. (1998) The effects of total quality management on corporate performance: An empirical investigation. Journal of Business, 71(2), 253-307.

Forrester, J.W. (1961) Industrial Dynamics. The MIT Press, Cambridge, MA.

Goldratt, E.M. (1990) What is this thing called theory of constraints and how should it be implemented. North River Press, Croton on Hudson, NY.

Hamel, G., and Prahalad, C. (1989) Strategic Intent. Harvard Business Review, 67(3), 63-77.

Hendricks, K., and Singhal, V. (1996) Quality awards and the market value of the firm: An empirical investigation. Management Science, 43(3), 415-436.

Ishikawa, K. (1985) What is total quality control? Prentice Hall, Englewood Cliffs, NJ.

Jones, A., Krahmer, E., Oliva, R., Repenning, N., Rockart, S., and Sterman, J. (1996). Comparing improvement programs for product development and manufacturing: Results from field studies. Paper presented at the Proceedings of the 1996 International System Dynamics Conference, Boston, MA.

Juran, J. (1969) Managerial breakthrough: A new concept of the manager's job. McGraw Hill, New York. 
Kahneman, D., and Lovallo, D. (1993) Timid choices and bold forecasts: A cognitive perspective on risk-taking. Management Science, 39(1), 17-31.

Keating, E., and Oliva, R. (forthcoming). A dynamic theory for sustaining process improvement teams in product development. In Beyerlein, M. and Johnson, D. (Eds.), Advances in interdisciplinary studies of teams: Product development teams (Vol. 5, ). Greenwich, CT: JAI Press.

Nakajima, S. (1988) Introduction to TPM: Total productive maintenance. Productivity Press, Cambridge, MA.

Oliva, R., Rockart, S., and Sterman, J. (1998). Managing multiple improvement efforts: Lessons from a semiconductor manufacturing site. In Fedor, D. and Ghosh, S. (Eds.), Advances in the Management of Organizational Quality (Vol. 3, pp. 1-55). Greenwich, CT: JAI Press.

Repenning, Nelson (1998). Drive out Fear (Unless You Can Drive it In): The role of agency and job security in process improvement. Working paper, available from author.

Repenning, N. and Sterman, J. (1997). Getting Quality the Old-Fashioned Way: Self-confirming attributions in the dynamics of process improvement. Forthcoming in Scott, R. and Cole, R., The quality movement in America: Lessons for theory and research. (Working paper available from authors.)

Schaffer, R., and Thomson, H. (1992) Successful change programs begin with results. Harvard Business Review, 70(1), 80-89.

Schneiderman, A. (1988) Setting quality goals. Quality Progress, April, 55-57.

Shewhart, W. (1939) Statistical Method from the Viewpoint of Quality Control . U.S. Department of Agriculture, Washington, DC.

Shiba, S., Graham, A., and Walden, D. (1993) A new American TQM: Four practical revolutions in management. Productivity Press and the Center for Quality Management, Cambridge, MA. 
Sterman, J., Banaghan, E., and Gorman, E. (1992) Learning to stitch in time: Building a proactive maintenance culture at E.I. Du Pont de Nemours and Co. Case study available from author. MIT, Sloan School of Management, Cambridge, MA 02142.

Sterman, J., Repenning, N., and Kofman, A. (1997) Unanticipated side effects of successful quality programs: Exploring a paradox of organizational improvement. Management Science, 43(4), 503-521.

Sterman, J., Repenning, N., Oliva, R., Krahmer, E., Rockart, S., and Jones, A. (1996). The improvement paradox: Designing sustainable quality improvement programs. Paper presented at the Proceedings of the 1996 International System Dynamics Conference, Boston, MA.

US General Accounting Office (1991) US companies improve performance through quality efforts 9-190. GAO/NSIAD.

Young, E. (1991a) International quality study - Best practices report . Ernst \& Young/American Quality Foundation, Milwaukee, WI.

Young, E. (1991b) International quality study - Top line findings . Ernst \& Young/American Quality Foundation, Milwaukee, WI.

Zangwill, W., and Kantor, P. (1998) Toward a theory of continuous improvement and the learning curve. Management Science, 44(7), 910-920. 